\title{
Adubação nitrogenada e potássica em soja sob sistemas de semeadura
}

\section{Angelo Henrique Canan Korber ${ }^{1}$, Luana Patricia Pinto ${ }^{2}$, Laércio Augusto Pivetta ${ }^{1}$, Leandro Paiola Albrecht ${ }^{1}$, Késia Damaris de Azevedo Frigo ${ }^{2}$}

\author{
${ }^{1}$ Universidade Federal do Paraná, Setor Palotina, Palotina, Paraná, Brasil. E-mail: angelohckorber@hotmail.com, \\ laerciopivetta@ufpr.br, lpalbrecht@ufpr.br \\ ${ }^{2}$ Universidade Estadual do Oeste do Paraná, Campus Cascavel, Cascavel, Paraná, Brasil. E-mail: luana.kozak@gmail.com, \\ kesia.damaris@gmail.com
}

Recebido: 10/05/2017; Aceito: 16/10/2017.

\section{RESUMO}

Atualmente, práticas agrícolas sustentáveis que contribuam para maximizar a produtividade da soja nos diversos sistemas de produção são de extrema importância para o agronegócio da cultura no Brasil. O objetivo deste trabalho foi avaliar o desempenho agronômico da soja em função da adubação nitrogenada e potássica em cobertura, em sistema de semeadura cruzada e simples. Em cada sistema de semeadura foram testadas doses de potássio $\left(\mathrm{K}_{2} \mathrm{O}\right)$ aplicadas de forma isolada ou combinada com nitrogênio $(\mathrm{N})$. Os experimentos foram instalados na safra de 2013/2014 e receberam a aplicação de 0, 20, 40, 60 e $80 \mathrm{~kg} \mathrm{ha}^{-1}$ de $\mathrm{K}_{2} \mathrm{O}$ e/ou N, totalizando quatro experimentos. Todos os experimentos foram delineados em blocos casualizados com quatro repetições. $\mathrm{Na}$ colheita foram avaliadas a altura de inserção da primeira vagem, altura de plantas, número de vagens, população final de plantas, massa de 100 grãos e produtividade. A adubação potássica de forma isolada ou combinada com $\mathrm{N}$ no estádio vegetativo V6 não afeta a produtividade da cultura, este fato relaciona-se com o alto teor de $\mathrm{K}$ no solo, a adubação potássica de semeadura e a adequada eficiência da FBN. Em sistema de semeadura de linhas simples, a adubação de cobertura de $\mathrm{K}$ com $35,1 \mathrm{~kg} \mathrm{ha}^{-1}$, totalizando $87,1 \mathrm{~kg} \mathrm{ha}^{-1}$, promove aumento da altura de plantas sem demonstrar efeito na produtividade.

Palavras-chave: Adubação de cobertura, produtividade, semeadura cruzada

\section{Nitrogen and potassium fertilization in soybean under planting systems}

\begin{abstract}
Sustainable agricultural practices that contribute to maximizing soybean yield in the various sowing and fertilization systems currently adopted are of the utmost importance for the agribusiness of the crop in Brazil. The objective of this work was to evaluate the agronomic performance of soybeans as a function of the nitrogen and potassium fertilization in topdressing, in a system of simple and crossed sowing. In each seeding system were tested potassium doses $\left(\mathrm{K}_{2} \mathrm{O}\right)$ applied singly or in combination with nitrogen $(\mathrm{N})$, both in the same proportion. The experiment was installed in the harvest 2013/2014, doses of $0,20,40,60$ and $80 \mathrm{~kg} \mathrm{ha}^{-1}$, in $\mathrm{K}_{2} \mathrm{O}$ and N, totaling four experiments. All experiments were designed in randomized blocks, with four replications. It were evaluated weight of 100 grains, grain yield, first pod height, plant height, number of pods and final plant population. Topdressing fertilization in the growth stage $\mathrm{V}_{6}$ with $\mathrm{K}$ alone or combined with $\mathrm{N}$ doesn't affect yield of crop, this fact is related to the high $\mathrm{K}$ content in the soil, the $\mathrm{K}$ fertilization of sowing and the adequate FBN efficiency. In a single row seeding system, the potassium topdressing with $35.1 \mathrm{~kg} \mathrm{ha}^{-1}$, totaling $87.1 \mathrm{~kg} \mathrm{ha}^{-1}$, promotes an increase in plant height without showing an effect on productivity.
\end{abstract}

Key words: Topdressing fertilizing; productivity, crossed seeding. 


\section{Introdução}

O cultivo da soja no Brasil iniciou em 1882 no estado da Bahia, expandindo-se em seguida para a região Sudeste do país, sendo hoje impulsionada pelo crescimento do consumo de soja, diretamente influenciado pelo consumo de carnes. O farelo de soja é amplamente utilizado em dietas suínas e avícolas, pelo motivo de ser de baixo custo por unidade proteica (PASTORE et al., 2014).

De acordo com os levantamentos feitos por Moreira (2016), a soja é a principal commoditie exportada pelo Brasil; cerca de 58,4 milhões de toneladas comercializados na safra de 2016/2017, observando um crescimento de $24 \%$ nos últimos cinco anos e em torno de $25 \%$ da necessidade de consumo brasileira. Segundo os dados da Conab (2017), as exportações brasileiras em fevereiro de 2017 foram de 3,59 milhões de toneladas a mais que o ano anterior, assim, juntamente com os EUA e Argentina, o Brasil comanda o cenário global do mercado da soja.

A soja é uma oleaginosa de importância econômica mundial. No Brasil, produzida em larga escala, a cultura destaca-se dentre outros fatores por ser mecanizável e pelo investimento em pesquisa e tecnologia por empresas, cooperativas e órgãos públicos que subsidiam aos produtores melhores condições de manejo e maior produtividade em suas áreas de cultivo.

Esta planta necessita de vários nutrientes para se desenvolver, sendo potássio $(\mathrm{K})$ o segundo nutriente mais exportado pela cultura da soja. Em média, são exportados em torno de $18,5 \mathrm{~kg}$ de $\mathrm{K}$ por tonelada de grãos produzidos (TANAKA; MASCARENHAS, 1992; PETTER et al., 2012). A deficiência de $\mathrm{K}$ no solo pode não só ocasionar deficiência severa visível nas plantas, mas, essa deficiência atuará diretamente no comprometimento da produtividade e qualidade dos grãos (SERAFIM et al., 2012).

$\mathrm{O} \mathrm{K}$ atua na ativação enzimática, na regulação de abertura e fechamento dos estômatos, no controle osmótico, dentre outras funções (MALAVOLTA, 2006; TAIZ; ZEIGER, 2012). A principal fonte de adubação potássica utilizada no Brasil é o cloreto de potássio $(\mathrm{KCl})$, um sal de alta solubilidade e de baixa força de adsorver em coloides do solo (GONÇALVES-JUNIOR et al., 2010; DUARTE et al., 2013). Por sua vez, o nitrogênio (N) faz parte da composição de alguns hormônios, clorofila, proteínas e ácidos nucleicos, sendo o nutriente exigido em maior quantidade pela maioria das culturas, principalmente pela soja (LORENSINI et al., 2014).

No Brasil tem sido pouco comum a prática de aplicação de $\mathrm{N}$ em cobertura na cultura da soja devido à alta eficiência da fixação biológica de nitrogênio (FBN) realizada pelas bactérias do gênero Bradyrhizobium em condições tropicais (AMADO et al., 2010).
De acordo com Aratani et al. (2008), a divergência entre os resultados relativos à eficiência da aplicação de $\mathrm{N}$ em cobertura na soja se deve à vários fatores como a eficiência da simbiose, cultivares, época de semeadura, fonte de $\mathrm{N}$, tipo de solo e fatores climáticos. A aplicação de nutrientes em cobertura é uma forma de buscar ganhos em características desejáveis da planta, no momento em que a cultura está implantada. Para fazer o melhor uso da área e ter melhor alocação de plantas, tem-se como alternativa benéfica a semeadura cruzada, o qual é baseado no ato de semear passadas de semeadora perpendiculares (SILVA et al, 2015).

Lima et al. (2012) expõe que este tipo de semeadura é naturalmente utilizada pelos produtores nas margens das áreas cultivadas de maneira a equilibrar e compensar as falhas que ocorrem nos locais de mobilidade dos equipamentos dentro da lavoura. Segundo Procópio et al. (2013), há estudos que demonstram alta produtividade de grãos de soja devido ao plantio feito na forma de semeadura cruzada. Balbinot-Júnior et al. (2015) afirmam que devido à esta técnica de semeadura ocorre maior mobilização de nutrientes do solo que podem influenciar no desenvolvimento da planta atingindo resultados na produtividade.

Dessa maneira, a semeadura cruzada é uma alternativa para se buscar incremento em produtividade na cultura da soja. Em função do exposto, este trabalho teve como objetivo avaliar o desempenho agronômico da soja em função da adubação nitrogenada e potássica em cobertura em semeadura cruzada e simples.

\section{Material e Métodos}

Os experimentos foram realizados no município de Palotina-PR na safra de 2013/2014 cuja região é caracterizada com altitude do terreno em torno de 340 metros, em Latossolo Vermelho Eutroférrico, com $72 \%$ de argila e relevo suave ondulado. A caracterização química do solo da área experimental está apresentada na Tabela 1 .

O clima local é subtropical de acordo com a classificação de Köppen como Cfa, apresentando verões quentes e precipitações anuais entre 1200 e 2000 mm distribuídos durante o ano e médias de temperaturas anuais de 17 e $19{ }^{\circ} \mathrm{C}$ (IAPAR, 2006). Os dados meteorológicos da área experimental durante a condução do ensaio estão apresentados na Figura 1.

Neste estudo, foram conduzidos quatro experimentos, sendo dois em sistema de semeadura simples e dois em sistema cruzado, todos delineados em blocos casualizados, com quatro repetições. O primeiro experimento teve como tratamentos a aplicação de cinco doses de potássio em cobertura $\left(0,20,40,60\right.$ e $80 \mathrm{~kg}$ ha ${ }^{-}$ ${ }^{1}$ de $\mathrm{K}_{2} \mathrm{O}$ ) em semeadura cruzada. 
Tabela 1. Caracterização química do solo na camada de $0,0-0,2 \mathrm{~m}$ antes da instalação do experimento

\begin{tabular}{|c|c|c|c|c|c|c|}
\hline $\mathrm{pH}$ & $\mathrm{K}$ & $\mathrm{Ca}$ & $\mathrm{Mg}$ & $\mathrm{H}+\mathrm{Al}$ & SB & CTC \\
\hline $\mathrm{CaCl}_{2}$ & & ----- & - & ----- & -------" & \\
\hline 5,10 & 0,48 & 5,46 & 1,95 & 4,61 & 7,89 & 12,50 \\
\hline $\mathrm{V}$ & $\mathrm{P}$ & $\mathrm{Fe}$ & $\mathrm{Cu}$ & $\mathrm{Zn}$ & $\mathrm{Mn}$ & $\mathrm{C}$ \\
\hline$\%$ & & 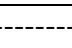 & $\mathrm{n}^{-3}-$ & & & $\mathrm{g} \mathrm{dm}^{-3}$ \\
\hline 63,12 & 22,5 & 11,0 & 3,4 & 6,8 & 162,0 & 21,8 \\
\hline
\end{tabular}

H + Al: acidez potencial extraído por tampão SMP; SB: soma de bases; CTC: capacidade de troca de cátions; C: carbono orgânico; V\%: saturação por bases; P, K, Cu, Zn, Fe e Mn extraídos por Mehlich-1; Ca e Mg: extraídos por KCl.

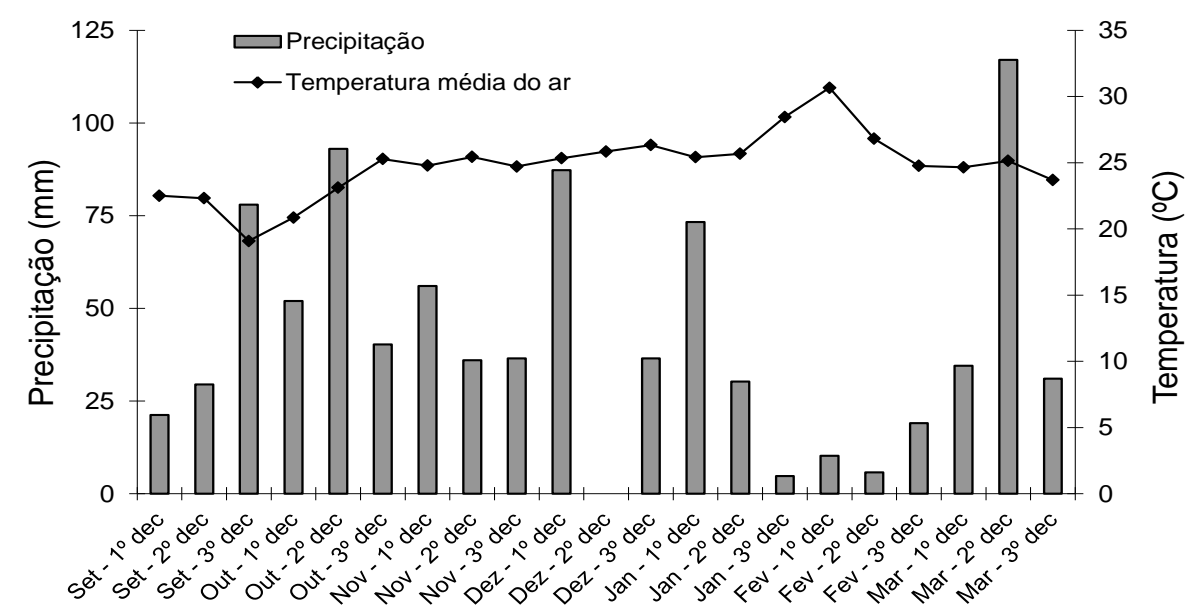

Figura 1. Precipitação acumulada e temperatura média por decêndio durante o período experimental, de setembro de 2013 a março de 2014. Palotina - PR.

O segundo experimento teve como tratamentos a combinação de diferentes doses de nitrogênio e potássio em cobertura $(0 / 0,20 / 20,40 / 40,60 / 60$ e $80 / 80 \mathrm{~kg}$ ha- 1 de $\mathrm{N} / \mathrm{K}_{2} \mathrm{O}$, respectivamente) em semeadura cruzada. $\mathrm{O}$ terceiro experimento teve como tratamentos a aplicação de cinco doses de potássio em cobertura $(0,20,40,60$ e $80 \mathrm{~kg} \mathrm{ha}^{-1}$ de $\mathrm{K}_{2} \mathrm{O}$ ) em semeadura simples. O quarto experimento teve como tratamentos a aplicação combinada de cinco doses de $\mathrm{N}$ e $\mathrm{K}_{2} \mathrm{O}$ conjugados em cobertura, 0/0, 20/20, 40/40, 60/60 e 80/80 kg ha ${ }^{-1}$ em semeadura simples. As parcelas tinham $12 \mathrm{~m}^{2}$ de área $(2,3 \mathrm{~m} \times 5,2 \mathrm{~m})$.

Foi utilizada a cultivar V-Max ${ }^{\circledR}$ convencional, que confere característica de hábito indeterminado, grau de maturação 6.2 e ciclo médio de 120 dias; semeada em setembro de 2013 de forma mecanizada com semeadora-adubadora, espaçamento entre linhas de 0,45 $\mathrm{m}$, densidade de semeadura de 400 mil sementes ha $^{-1}$ (18 sementes $\left.\mathrm{m}^{-1}\right)$, profundidade de $5 \mathrm{~cm}$, adubação de base de 5,8, 58 e $52 \mathrm{~kg} \mathrm{ha}^{-1}$ de $\mathrm{N}, \mathrm{P}_{2} \mathrm{O}_{5}$ e $\mathrm{K}_{2} \mathrm{O}$, respectivamente. A expectativa de produtividade era de $6.000 \mathrm{~kg} \mathrm{ha}^{-1}$. Na semeadura cruzada, foi usado o dobro de sementes e de adubo na base pelo efeito cumulativo das 2 passadas na mesma área. A quantidade de $\mathrm{N}$ e $\mathrm{K}$ de cobertura (estádio V6) foi semelhante à utilizada na semeadura simples. Utilizou-se como fertilizante ureia e cloreto de potássio $(\mathrm{KCl})$.
Considerando-se a adubação de semeadura de 52 e $104 \mathrm{~kg} \mathrm{ha}^{-1}$ de $_{2} \mathrm{O}$, nos sistemas de semeadura simples e cruzado, respectivamente, as doses totais aplicadas foram de 52, 72, 92, 112 e $132 \mathrm{~kg} \mathrm{ha}^{-1}$ de $\mathrm{K}_{2} \mathrm{O}$ no sistema simples e de 104, 124, 144, 164 e $184 \mathrm{~kg} \mathrm{ha}^{-1} \mathrm{de}$ $\mathrm{K}_{2} \mathrm{O}$ no sistema cruzado.

As sementes foram previamente tratadas com piraclostrobina, fipronil e tiofanato metílico (produto comercial Standak Top ${ }^{\circledR}$ ). Foi feita a inoculação da soja com inoculante líquido de nome comercial Gelfix $5^{\circledR}$, composto por bactérias Bradyrhizobium elkanii, na concentração de 5x109 UFC mL ${ }^{-1}$, na dose de $100 \mathrm{~mL}$ para cada $50 \mathrm{~kg}$ de sementes, misturado logo antes da semeadura em um tanque misturador.

Os tratos culturais da lavoura foram baseados na presença de pragas, plantas daninhas e doenças. Somente o fungicida foi aplicado de forma preventiva para Phakopsora pachyrhizi (ferrugem asiática).

Foram realizadas medições de altura da planta, altura da inserção da primeira vagem, número de vagens por planta, população, produtividade. As plantas foram colhidas inteiras e armazenadas em sacos, que foram debulhados mecanicamente. As amostras foram identificadas, pesadas, acondicionadas em estufa com circulação forçada de ar a $70^{\circ} \mathrm{C}$ por 96 horas e pesadas novamente. A produtividade da parcela foi convertida em kg ha ${ }^{-1}$, com umidade ajustada a $13 \%$. 
A quantificação da massa de 100 grãos foi realizada por meio de oito repetições da massa de 100 grãos que também foi secado na estufa da mesma forma em que na avaliação de produtividade, corrigido o valor para $13 \%$ de umidade, e calculada a média.

Os dados foram submetidos à análise de variância e as médias comparadas pela análise de regressão, para as doses de K, e pelo teste de Tukey, para as adubações conjuntas de $\mathrm{N}$ e $\mathrm{K}$, ambos a $5 \%$ de probabilidade, utilizando o software estatístico Sisvar versão 5.

\section{Resultados e Discussão}

De acordo com os dados obtidos, a adubação potássica em cobertura não afetou significativamente ( $>0,05)$ os componentes de produção e a produtividade da soja em sistema de semeadura cruzada (Tabela 2). Os resultados no sistema de semeadura simples (convencional) constam na Tabela 3.

A semeadura cruzada, segundo Silva et al. (2015), consiste em semear a área em duas passadas com a semeadora, de modo que a segunda se apresente perpendicular à primeira; surge então a hipótese de que ao dobrar a população, aumenta-se a demanda nutricional da cultura sendo necessário a suplementação de N e K. Seguindo outra hipótese, a semeadura cruzada pode ser um arranjo espacial mais bem distribuído e aproveitar melhor os nutrientes das entrelinhas, demandando menos acréscimo de nutrientes.

Nos trabalhos de Balbinot-Júnior et al. (2016), Hirakuri et al. (2017), Ribeiro et al (2017) e Rodrigues et al. (2017) não foi observada diferença significativa para os parâmetros de produção e produtividade avaliados, ou seja, a semeadura cruzada é um manejo que não difere. Constatou-se falhas de germinação nos quatro experimentos, provavelmente influenciada pela profundidade da semeadura juntamente à intensidade de chuvas logo após a semeadura. No entanto, a soja tem a capacidade de tolerar variações amplas de população, alterando mais sua estrutura morfológica que a produtividade, fato que ocorre pela sua alta capacidade de compensar o espaço entre plantas (SOUZA et al., 2014).

A soja apresentou ponto de máxima da equação de $84,3 \mathrm{~cm}$, correspondendo à dose de $35,1 \mathrm{~kg} \mathrm{ha}^{-1}$ de $\mathrm{K}_{2} \mathrm{O}$. É válido destacar que como a adubação de semeadura constou de $52 \mathrm{~kg} \mathrm{ha}^{-1}$ de $\mathrm{K}_{2} \mathrm{O}$; a máxima altura foi atingida com $87,1 \mathrm{~kg} \mathrm{ha}^{-1}$ de $\mathrm{K}_{2} \mathrm{O}$. Apesar deste efeito na altura de plantas, salienta-se que o objetivo final é a produtividade de grãos, o que não foi afetado pelas doses de potássio. Contudo, o fato da soja ter apresentado maior crescimento demonstra que a cultura não foi insensível ao $\mathrm{K}$ aplicado.

Tabela 2. Efeito da adubação potássica de cobertura nos componentes de produção e na produtividade da soja cv. V-Max ${ }^{\circledR}$ em sistema de semeadura cruzada

\begin{tabular}{|c|c|c|c|c|c|c|c|}
\hline \multirow[t]{2}{*}{ Dose de $\mathrm{K}_{2} \mathrm{O}$} & \multirow{2}{*}{$\begin{array}{l}\text { M100 } \\
(\mathrm{g})\end{array}$} & \multirow{2}{*}{$\begin{array}{c}\text { Produtividade } \\
\mathrm{kg} \mathrm{ha}^{-1}\end{array}$} & Altura $1^{\circ}$ vagem & Altura de Plantas & \multirow{2}{*}{ Número de vagens } & \multirow{2}{*}{$\begin{array}{c}\text { Pop. } \\
\left(\text { Plantas ha }^{-1}\right)\end{array}$} & \multirow{2}{*}{$\begin{array}{c}\text { Sob. } \\
\%\end{array}$} \\
\hline & & & \multicolumn{2}{|c|}{$(\mathrm{cm})$} & & & \\
\hline 0 & 14,09 & 2.478 & 8,69 & 91,25 & 36,25 & 245.000 & 31 \\
\hline 20 & 13,51 & 2.199 & 8,38 & 88,75 & 41,42 & 245.000 & 31 \\
\hline 40 & 14,29 & 2.382 & 7,97 & 85,5 & 40,08 & 297.500 & 37 \\
\hline 60 & 13,83 & 2.410 & 7,94 & 90,5 & 34,00 & 287.500 & 36 \\
\hline 80 & 15,34 & 2.643 & 7,08 & 83,5 & 40,83 & 232.500 & 29 \\
\hline $\mathrm{CV}(\%)$ & 6,51 & 11,43 & 21,1 & 6,24 & 14,81 & 23,42 & 32,69 \\
\hline F calc & $2,24^{\mathrm{ns}}$ & $1,35^{\mathrm{ns}}$ & $0,51^{\mathrm{ns}}$ & $1,46^{\mathrm{ns}}$ & $1,28^{\mathrm{ns}}$ & $0,90^{\mathrm{ns}}$ & \\
\hline
\end{tabular}

CV: coeficiente de variação; M100: massa de 100 grãos. ns: não significativo; Pop: população; Sob: sobrevivência.

Tabela 3. Efeito da adubação potássica de cobertura nos componentes de produção e na produtividade da soja cv. V-Max ${ }^{\circledR}$ em sistema de semeadura simples (convencional)

\begin{tabular}{|c|c|c|c|c|c|c|}
\hline \multirow[t]{2}{*}{ Dose de $\mathrm{K}_{2} \mathrm{O}$} & \multirow{2}{*}{$\begin{array}{l}\text { M100 } \\
\text { (g) }\end{array}$} & \multirow{2}{*}{$\begin{array}{c}\text { Produtividade } \\
\qquad \mathrm{kg} \mathrm{ha}^{-1}\end{array}$} & $\begin{array}{c}\text { Altura } 1^{\mathrm{a}} \\
\text { vagem }\end{array}$ & $\begin{array}{c}\text { Número de } \\
\text { vagens }\end{array}$ & \multirow{2}{*}{$\begin{array}{l}\text { População } \\
\left(\text { Plantas ha }^{-1}\right)\end{array}$} & \multirow{2}{*}{$\begin{array}{c}\text { Sobrevivência } \\
\%\end{array}$} \\
\hline & & & \multicolumn{2}{|c|}{$(\mathrm{cm})$} & & \\
\hline 0 & 14,96 & 2.276 & 7,15 & 41,34 & 350.000 & 87 \\
\hline 20 & 14,77 & 2.080 & 6,56 & 45,5 & 325.000 & 81 \\
\hline 40 & 14,26 & 2.274 & 7,72 & 53,59 & 272.500 & 68 \\
\hline 60 & 14,78 & 1.898 & 7,05 & 46,67 & 357.500 & 89 \\
\hline 80 & 14,62 & 2.030 & 7,3 & 48,25 & 317.500 & 79 \\
\hline $\mathrm{CV}(\%)$ & 7,47 & 16,74 & 13,21 & 13,91 & 19,94 & 81,13 \\
\hline F calc & $0,23 \mathrm{~ns}$ & $0,85 \mathrm{~ns}$ & $0,78 \mathrm{~ns}$ & $1,86 \mathrm{~ns}$ & $1,07 \mathrm{~ns}$ & \\
\hline
\end{tabular}

CV: coeficiente de variação; M100: massa de 100 grãos. ns: não significativo. 
Valicheski et al. (2012) consideram que o crescimento vegetativo compete com a produção de grãos, mas altas produtividades de grãos podem ser obtidas com plantas que apresentem crescimento vegetativo vigoroso, desde que sejam capazes de translocar os fotoassimilados para os grãos. Independente do sistema de semeadura, a soja não apresentou alterações na massa de 100 grãos, produtividade, altura de inserção da $1^{\mathrm{a}}$ vagem, número de vagens e população em função das doses de $\mathrm{K}$ em cobertura. A exceção foi a altura de plantas na semeadura simples.

A principal explicação para a ausência de resposta da soja é o alto teor de $\mathrm{K}$ no solo, aliado à aplicação de $\mathrm{K}$ na semeadura. A análise de solo revelou que havia $0,48 \mathrm{cmol}_{\mathrm{c}} \mathrm{dm}^{-3}$ de $\mathrm{K}$ no solo, ou seja, um alto teor visto que a dose recomendada para solos com teores de argila maiores que $400 \mathrm{~g} \mathrm{~kg}^{-1}$ e potássio acima de 0,30 $\mathrm{cmol}_{\mathrm{c}}$ $\mathrm{dm}^{-3}$ é de $40 \mathrm{~kg} \mathrm{ha}^{-1}$ de $\mathrm{K}_{2} \mathrm{O}$ (MALAVOLTA, 2006; SILVA; LAZARINI, 2014).

De acordo com Hurtado et al. (2008), em sistemas de produção de grãos mais avançados, em áreas que se produz a mais de 5 anos, é normal encontrar teores de $\mathrm{K}$ no solo muito acima de $0,30 \mathrm{cmol}_{\mathrm{c}} \mathrm{dm}^{-3}$. Não há relatos de toxidez causados pelo potássio às plantas. Em trabalho de 12 anos com adubação potássica, Scherer (1998), mostra que em Latossolo Húmico distrófico, teores de potássio acima de $0,32 \mathrm{cmol}_{\mathrm{c}} \mathrm{dm}^{-3}$ são o suficiente para se produzir com rendimentos máximos de soja, nos primeiros 4 anos, tornando-se desnecessária a adubação potássica. O mesmo autor afirma que a aplicação anual de $60 \mathrm{~kg} \mathrm{ha}^{-1}$ de $\mathrm{K}_{2} \mathrm{O}$ é o suficiente para manter o teor de $\mathrm{K}$ no solo e atingir $90 \%$ da produção máxima da cultura. $\mathrm{O}$ autor demonstrou também que a aplicação de $320 \mathrm{~kg} \mathrm{ha}^{-1}$ de $\mathrm{K}_{2} \mathrm{O}$ apresentou prolongado efeito residual, mantendo a produtividade satisfatória por seis cultivos de soja, ou seja, nos seis anos subsequentes ainda se produziu mais que a testemunha não adubada.
Em solos com altos teores de potássio, a cultura não apresenta diferença em produtividade. Santos (2012) demonstra resultados semelhantes, onde a época de aplicação não interfere na produtividade e na massa de 1000 grãos, assim também corroboram os trabalhos de Foloni e Rosolem (2008), ressaltando que a adubação potássica pode ser totalmente adiantada na semeadura do milheto em cobertura, em sucessão milheto-soja, não alterando em produtividade, porém as doses de 85 a 90 $\mathrm{kg} \mathrm{ha}^{-1}$ de $\mathrm{K}_{2} \mathrm{O}$ apresentam melhores resultados em produtividade.

A produtividade se apresentou baixa provavelmente pela estiagem observada em dezembro de 2013 coincidindo com a época de enchimento de grãos. Os dados de pluviosidade e temperatura do ar foram coletados pela cooperativa Cvale em outra área, contudo na área destes experimentos houve estiagem mais severa em comparação à outras regiões.

$\mathrm{Na}$ semeadura, na ocasião da segunda passada da semeadora, o solo já se encontrava solto causado pela primeira passada, desta maneira, a segunda teve a profundidade maior, assim como efeito de arrasto de grãos no momento da segunda passada, o que pode ter acarretado as falhas de emergência das plantas e ocasionado queda de produtividade. O parâmetro de massa de 100 grãos está diretamente relacionado com produtividade de grãos. O trabalho não apresentou diferença estatística das médias de massa de 100 grãos em nenhuma das doses nos 4 experimentos, denotando que as doses de potássio em cobertura não interferem na massa de 100 grãos em solos de alta disponibilidade de potássio, assim como o nitrogênio conjugado com o potássio também não interferiu.

A adubação conjugada de $\mathrm{N}$ e $\mathrm{K}$ em cobertura na soja em sistema de semeadura cruzada (Tabela 4) e semeadura simples (Tabela 5) não apresentou efeito significativo para nenhum dos parâmetros avaliados.

Tabela 4. Efeito da combinação da adubação potássica e nitrogenada em cobertura nos componentes de produção e na produtividade da soja cv. V-Max ${ }^{\circledR}$ em sistema de semeadura cruzada

\begin{tabular}{|c|c|c|c|c|c|c|c|}
\hline \multirow{2}{*}{$\begin{array}{l}\text { Dose de N- } \\
\qquad \mathrm{K}_{2} \mathrm{O}\end{array}$} & \multirow{2}{*}{$\begin{array}{l}\text { M100 } \\
\text { (g) }\end{array}$} & \multirow{2}{*}{$\begin{array}{l}\text { Produtividade } \\
\qquad \mathrm{kg} \mathrm{ha}^{-1}\end{array}$} & $\begin{array}{c}\text { Altura } 1^{\circ} \\
\text { vagem }\end{array}$ & $\begin{array}{c}\text { Altura de } \\
\text { Plantas }\end{array}$ & \multirow[t]{2}{*}{$\begin{array}{l}\mathrm{N}^{\text {o de }} \\
\text { vagens }\end{array}$} & \multirow{2}{*}{$\begin{array}{c}\text { Pop. } \\
\left(\text { Plantas ha }^{-1}\right)\end{array}$} & \multirow{2}{*}{$\begin{array}{c}\text { Sob. } \\
\%\end{array}$} \\
\hline & & & \multicolumn{2}{|c|}{$(\mathrm{cm})$} & & & \\
\hline $0-0$ & 14,91 & 2.368 & 7,27 & 90,75 & 41,16 & 282.500 & 35 \\
\hline $20-20$ & 14,37 & 2.376 & 7,43 & 86,5 & 39,66 & 267.500 & 33 \\
\hline $40-40$ & 13,97 & 2.074 & 6,92 & 84,5 & 39,41 & 292.500 & 37 \\
\hline $60-60$ & 14,98 & 2.435 & 6,66 & 83,5 & 41,5 & 230.000 & 29 \\
\hline $80-80$ & 14,39 & 2.396 & 7 & 86,25 & 43,08 & 292.500 & 37 \\
\hline CV (\%) & 9,29 & 10,91 & 15,3 & 3,9 & 16,02 & 17,18 & 34,13 \\
\hline F calc & $0,38 \mathrm{~ns}$ & $1,31 \mathrm{~ns}$ & $0,21 \mathrm{~ns}$ & $2,73 \mathrm{~ns}$ & $0,31 \mathrm{~ns}$ & $1,24 \mathrm{~ns}$ & \\
\hline
\end{tabular}

CV: coeficiente de variação; M100: massa de 100 grãos; ns: não significativo; Pop: população; Sob: sobrevivência. 
Tabela 5. Efeitos da combinação da adubação potássica e nitrogenada em cobertura nos componentes de produção e na produtividade da soja cv. V-Max ${ }^{\circledR}$ em sistema de semeadura simples

\begin{tabular}{|c|c|c|c|c|c|c|c|}
\hline \multirow{2}{*}{$\begin{array}{l}\text { Dose de N- } \\
\qquad \mathrm{K}_{2} \mathrm{O}\end{array}$} & M100 & Produtividade & $\begin{array}{c}\text { Altura } 1^{\circ} \\
\text { vagem }\end{array}$ & $\begin{array}{l}\text { Altura de } \\
\text { Plantas }\end{array}$ & \multirow[t]{2}{*}{$\mathrm{N}^{\mathrm{o}}$ de vagens } & \multirow{2}{*}{ 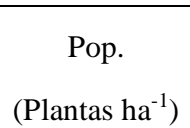 } & \multirow{2}{*}{$\begin{array}{c}\text { Sob. } \\
\%\end{array}$} \\
\hline & (g) & $\mathrm{kg} \mathrm{ha}^{-1}$ & \multicolumn{2}{|c|}{$(\mathrm{cm})$} & & & \\
\hline $0-0$ & 14,55 & 2.068 & 6,46 & 79,5 & 43,83 & 310.000 & 77 \\
\hline $20-20$ & 14,34 & 2.027 & 7,53 & 83,25 & 47 & 315.000 & 79 \\
\hline $40-40$ & 14,06 & 1.878 & 7,29 & 80,75 & 42,08 & 327.500 & 82 \\
\hline $60-60$ & 13,47 & 1.989 & 7,14 & 80,25 & 45,08 & 322.500 & 81 \\
\hline $80-80$ & 13,99 & 2.276 & 6,95 & 83,25 & 41,16 & 260.000 & 65 \\
\hline $\mathrm{CV}(\%)$ & 10,29 & 13,6 & 12,3 & 7,69 & 20,21 & 25,63 & 76,75 \\
\hline F calc & $0,319 \mathrm{~ns}$ & $1,10 \mathrm{~ns}$ & $0,87 \mathrm{~ns}$ & $0,31 \mathrm{~ns}$ & $0,28 \mathrm{~ns}$ & $0,48 \mathrm{~ns}$ & \\
\hline
\end{tabular}

CV: coeficiente de variação; M100: massa de 100 grãos; ns: não significativo; Pop: população; Sob: sobrevivência.

De acordo com Thorburn et al. (2011), a adubação nitrogenada afeta negativamente $\mathrm{o}$ processo de nodulação e fixação de nitrogênio, visto que esta tem relação direta com a massa nodular, porém torna-se necessário fazer adubação nitrogenada em soja de inverno. Isso foi constatado também no trabalho de Tanaka e Mascarenhas (1992), observando que a simbiose não foi capaz de suprir o nitrogênio demandado pela planta em soja cultivada no inverno, provavelmente pela condição de menor quantidade de fotossintetizados, consequência da baixa temperatura da época do ano.

Uma possibilidade para a ausência de efeito da adubação nitrogenada é a época de aplicação do Nitrogênio. Gan et al. (2003), Bernis e Viana (2015), observaram que aplicações foliares de $50 \mathrm{~kg} \mathrm{ha}^{-1}$ de $\mathrm{N}$ nos estádios V2 e R1 apresentaram aumento de produtividade em três cultivares; contudo nos estádios R3 e R5 não houve efeito do N.

Em outro experimento do mesmo grupo de pesquisa de Gan et al. (2002), foi observado o aumento de produtividade da soja mais pronunciado com a aplicação de $50 \mathrm{~kg} \mathrm{ha}^{-1}$ de $\mathrm{N}$ no estádio R5 associado com $25 \mathrm{~kg} \mathrm{ha}^{-1}$ de $\mathrm{N}$ na semeadura. Vale destacar que neste último trabalho os autores não compararam com uma testemunha sem adubação nitrogenada. Pode-se notar que os estádios considerados mais responsivos à adubação nitrogenada foram diferentes do utilizado neste experimento, o V6.

Aplicações tardias de $\mathrm{N}$, na fase reprodutiva, são recomendadas por considerar que a intensa translocação de carboidratos para as estruturas reprodutivas reduz o fornecimento destes carboidratos para os bacteróides, reduzindo a eficiência da FBN. As aplicações no início do ciclo da cultura são recomendadas por considerar que a nodulação não está estabelecida, suprindo uma deficiência momentânea de $\mathrm{N}$ à soja, ressaltando também que o $\mathrm{N}$ inorgânico é necessário para a formação e desenvolvimento do próprio nódulo (COOPER; SCHERER, 2012).
Em ambos os sistemas de semeadura, a adubação conjugada de $\mathrm{N}$ e $\mathrm{K}$ não apresentou alterações na produtividade de grãos e nos demais parâmetros avaliados, o que demonstra que a FBN foi eficiente em suprir N à soja. A FBN é feita por bactérias do gênero Bradyrhizobium, suprindo a necessidade de nitrogênio na soja e possibilitando a redução de custos, sendo possível substituir a adubação nitrogenada mineral e torna possível elevar o rendimento de grãos (HUNGRIA et al., 2005; SILVA et al., 2011).

Contudo, muitas destas hipóteses não são bem estabelecidas para as condições de cultivo do Brasil, onde a FBN em soja tem se mostrado mais eficiente que nos demais países.

\section{Conclusões}

A cultura da soja não responde de forma significativa a adubação potássica de cobertura em solos com alta disponibilidade de potássio no solo.

Os sistemas de semeadura em linhas cruzadas ou simples não resultam em efeitos significativos nos componentes de produção e na produtividade na cultura da soja.

A adubação nitrogenada em cobertura não afeta a produtividade da cultura da soja sendo necessário novos estudos para definição da melhor época de aplicação.

Em sistema de semeadura de linhas simples, a adubação de cobertura com $35,1 \mathrm{~kg} \mathrm{ha}^{-1}$, totalizando $87,1 \mathrm{~kg} \mathrm{ha}^{-1}$, promove aumento da altura de plantas.

\section{Referências Bibliográficas}

AMADO, T. J. C.; SCHLEINDWEIN, J. A.; FIORIN, J. E. Manejo do solo visando à obtenção de elevados rendimentos de soja sob sistema plantio direto. Porto Alegre-RS: Evangraf, 2010. p. 53-112.

ARATANI， R. G.; LAZARINI， E.; MARQUES，R. R.; BACKES, C. Nitrogen fertilization in soybean in no tillage system introduction. Bioscience Journal, Uberlândia-MG, v. 24, n. 3, p. 31-38, 2008. 
BALBINOT JUNIOR, A. A.; PROCOPIO, S. O.; COSTA, J. M.; KOSINSKI, C. L.; PANISON, F.; DEBIASI, H., FRANCHINI, J. C. Espaçamento reduzido e plantio cruzado associados a diferentes densidades de plantas em soja. Semina: Ciências Agrárias, Londrina-PR, v. 36, n. 5, p.29772986, 2015.

BALBINOT JUNIOR, A. A.; PROCÓPIO, S. O.; NEUMAIER, N.; FERREIRA, A. S.; WERNER, F.; DEBIASI, H.; FRANCHINI, J. C. Semeadura cruzada, espaçamento entre fileiras e densidade de semeadura influenciando o crescimento e a produtividade de duas cultivares de soja. Revista de Ciências Agroveterinárias, Lages-SC, v. 15, n. 2, p.83-93, 2016.

BERNIS, D. J.; VIANA, O. H. Influência da aplicação de nitrogênio via foliar em diferentes estágios fenológicos da soja. Cultivando o Saber. ed. esp, Cascavel-PR: FAG, 2015. p. 88-97.

CONAB. COMPANHIA NACIONAL DE ABASTECIMENTO. Acompanhamento da safra brasileira de grãos. v. 4 - Safra 2016/17, n. 7. - Sétimo levantamento, abril 2017.2 Disponível em: http://www.conab.gov.br/OlalaCMS/uploads/arquivos/17_04_ 17_17_20_55_boletim_graos_abr_2017.pdf

COOPER, J. E.; SCHERER, H. W. Nitrogen Fixation. In: MARSCHNER, P. Mineral Nutrition of Higher Plants, San Diego: Elsevier, 2012. p. 389-408.

DUARTE, I. N.; PEREIRA, H. S.; KORNDORFER, G. H. Ligações do sal cloreto de potássio. Pesquisa Agropecuária Tropical, Goiânia-GO, v. 43, n. 2, p. 195-200, 2013

FOLONI, J. S. S.; ROSOLEM, C. A. Produtividade e acúmulo de potássio na soja em função da antecipação da adubação potássica no sistema plantio direto. Revista Brasileira de Ciência do Solo, Viçosa-MG, v. 32, n. 2, p. 1549-1561, 2008.

GAN, Y.; STULEN, I.; POSTHUMUS, F.; KEULEN, H.; KUIPER, P. J. C. Effects of $\mathrm{N}$ management on growth, $\mathrm{N}$ fixation and yield of soybean. Nutrient Cycling in Agroecosystems, Ithaca: Springer, v. 62, n. 2, p. 163-174, 2002.

GAN, Y.; STULEN, I.; KEULEN, H.; KUIPER, P. J. C. Effect of $\mathrm{N}$ fertilizer top-dressing at various reproductive stages on growth, N2 fixation and yield of three soybean (Glycine max (L.) Merr.) genotypes. Field Crops Research, California, v. 80, p. 147-155, 2003.

GONÇALVES JÚNIOR, A. C.; NACKE, H.; MARENGONI, N. G.; CARVALHO, E. A.; COELHO, G. F. Produtividade e componentes de produção da soja adubada com diferentes doses de fósforo, potássio e zinco. Ciência Tecnológica, Lavras-MG, v. 34, n. 3, p. 660-666, 2010.

HIRAKURI, M. H.; CONTE, O.; BALBINOT JUNIOR, A. A. Análise econômica de diferentes arranjos espaciais de plantas de soja. Londrina-PR: Embrapa Soja. 2017. 8 p.

HUNGRIA, M., FRANCHINI, J. C., CAMPO, R. J., GRAHAM, P. H. The importance of nitrogen fixation to soybean cropping in South America. In: WERNER, D.; NEWTON, W., eds. Nitrogen fixation in agriculture, forestry, ecology and the environment. Dordrecht: Springer, 2005. p. $25-42$.
HURTADO, S. M. C; RESENDE, A. V.; CORAZZA, E. J.; SHIRATSUCHI, L. S.; HIGASHIKAWA, F. S. Otimização da adubação em lavouras com altos teores de potássio no solo. Revista Plantio Direto, Passo Fundo-RS, v. 106, n. 1, p.1-4, 2008.

IAPAR. INSTITUTO AGRONÔMICO DO PARANÁ. Cartas climáticas do Paraná. 2006. Disponível em: <http://200.201.27.14/Site/Sma/Cartas_Climaticas/Classificac ao_Climatica.htm>. Acesso em: 15/05/2015.

JÚLIO, O. L. L.; ASCARI, J. P.; MENDES, I. R. N.; SANTOS, E. S.; DUARTE, W. M.; NIED, A. H. Formas de adubação potássica e produtividade da cultura da soja. Revista Agrarian, Dourados-MS, v. 9, n. 32, p.149-155, 2016.

LORENSINI, F.; CERETTA, C. A.; BRUNETTO, G.; CERINI, J. B.; LOURENZI, C. R.; CONTI, L.; TIECHER, T. L.; SCHAPANSKI, D. E. Disponibilidade de nitrogênio de fontes minerais e orgânicas aplicadas em um Argissolo cultivado com videira. Revista Ceres, Viçosa-MG, v. 61, n. 2, p. 241-247, 2014

MALAVOLTA, E. Manual de nutrição mineral de plantas. 2. ed. São Paulo-SP: Ceres, 638 p. 2006.

MASCARENHAS, H. A. A.; TANAKA, R. T.; WUTKE, E. B.; BRAGA, N. R.; MIRANDA, M. A. C. de. Potássio para a soja. Piracicaba-SP: Potafos, 2004. 2 p.

MOREIRA, M. G. Soja - Análise da Conjuntura Agropecuária - Novembro, 2016, Paraná - Safra 2016/17. Brasília-DF: Conab, 2016. 18 p.

PASTORE, S. M.; OLIVEIRA, W. P.; BRUMANO, G. Mercado de milho, farelo de soja e ovos no Brasil de 2010 a 2013. Revista Eletrônica Nutritime, Viçosa-MG, v. 11, n. 1, p. 2982-3006, 2014

PETTER, F. A.; SILVA, J. A.; PACHECO, L. P.; ALMEIDA, F. A.; ALCANTARA NETO, F.; ZUFFO, A. M.; LIMA, L. B. Desempenho agronômico da soja a doses e épocas de aplicação de potássio no cerrado piauiense. Revista de Ciências Agrárias Amazonian Journal of Agricultural And Environment of Sciences, Manaus-AM, v. 55, n. 3, p.190196, set. 2012

PROCÓPIO S. O.; BALBINOT JUNIOR, A. A.; DEBIASI, H.; FRANCHINI, J. C.; PANISON, F. Plantio cruzado na cultura da soja utilizando uma cultivar de hábito de crescimento indeterminado. Revista de Ciências Agrárias, Manaus-AM, v. 56, n. 4, p 319-325, 2013.

RIBEIRO, A. B. M.; BRUZI, A. T.; ZUFFO, A. M.; ZAMBIAZZI, E. V.; SOARES, I. O.; VILELA, N. J. D.; PEREIRA, J. L. A. R.; MOREIRA, S. G. Productive performance of soybean cultivars grown in different plant densities. Ciência Rural, Santa Maria-RS, v. 47, n. 7, p.1-8, maio 2017.

RODRIGUES, A. R.; ABREU, M. L.; OLIVEIRA, E. S. Cultivo da soja em sistemas de semeadura em linhas cruzadas e convencional. Energia na Agricultura, São Paulo-SP, v. 32, n. 1, p.1-8, jan. 2017.

SANTOS, R.; VARGAS G. R. Efeito da adubação potássica na produtividade da soja. Publicatio UEPG, Ponta GrossaPR, v. 18. n. 2, p.79-84, 2012. 
SCHERER, E. E. Resposta da soja a adubação potássica em Latossolo húmicodistrófico num período de doze anos. Revista Brasileira de Ciência do Solo, Campinas-SP, v. 22, n. 1, p. 49-55, 1998.

SERAFIM, M. E.; ONO, F. B.; ZEVIANI, W. M.; NOVELINO, J. O.; SILVA, J. V. Umidade do solo e doses de potássio na cultura da soja. Ciência Agronômica, FortalezaCE, v. 43, n. 2, p. 222-227, 2012.

SILVA, A. F.; CARVALHO, M. A. C.; SCHONINGER, E. L.; MONTEIRO, S.; CAIONE, G., SANTOS, P. A. Doses de inoculante e nitrogênio na semeadura da soja em área de primeiro cultivo. Bioscience Journal, Uberlândia-MG, v. 27, n. 3, p. 404-412, 2011.

SILVA, A. F.; LAZARINI, E. Doses e épocas de aplicação de potássio na cultura da soja em sucessão a plantas de cobertura. Ciências Agrárias, Londrina-PR, v. 35, n. 1, p. 179-192, 2014

SILVA, P. R. A.; TAVARES, L. A. F.; SOUSA, S. F. G.; CORREIA, T. P. S; RIQUETTI, N. B. Rentabilidade na semeadura cruzada da cultura da soja. Revista Brasileira Engenharia Agrícola Ambiental, Campina Grande-PB, v. 19, n. 3, p. 293-297, 2015.
SOUZA, V. Q.; NARDINO, M.; FOLLMANN, D. N.; BAHRY, C. A.; CARON, B. O. ZIMMER, P. D. Caracteres morfofisiológicos e produtividade da soja em razão da desfolha no estádio vegetativo. Científica, Jaboticabal-SP, v. 42, n. 3, p. 216-223, 2014.

TAIZ, L; ZEIGER, E. Fisiologia Vegetal. 5. ed. Porto AlegreRS: Artmed, 2012, 720 p.

TANAKA, R. T.; MASCARENHAS, H. A. A. Soja, nutrição correção do solo e adubação. Campinas-SP: Fundação Cargill, 1992. 60 p. (Série Técnica, 7).

THORBURN, P. J.; BIGGS, J. S.; WEBSTER, A. J.; BIGGS, I. M. An improved way to determine nitrogen fertiliser requirements of sugarcane crops to meet global environmental challenges. Plant and Soil, The Hague, v. 339, n. 1-2, p. 5167, 2011.

VALICHESKI, R. R.; GROSSKLAUS, F; STURMER, S. L. K.; TRAMONTIN, A. L.; BAADE, E. S. A. S. Desenvolvimento de plantas de cobertura e produtividade da soja conforme atributos físicos em solo compactado. Revista Brasileira Engenharia Agrícola Ambiental, Campina Grande-PB, v. 16, n. 9, p. 969-977, 2012. 